\title{
Hepatoprotective Effect of Aqueous Extract of Gyrocarpus asiaticus on Paracetamol Induced Hepatotoxicity in Zebra Fish
}

\author{
Baisakhi Moharana $^{1^{*}}$, S.P. Preetha ${ }^{2}$, C. Balachandran ${ }^{3}$ and P. Acharya ${ }^{4}$ \\ ${ }^{1}$ Division of Pharmacology, CSIR-CDRI, Lucknow \\ ${ }^{2}$ Department of Veterinary Pharmacology and Toxicology, \\ Madras Veterinary College, TANUVAS, Chennai, India \\ ${ }^{3}$ Vice chancellor, TANUVAS, Chennai, India \\ ${ }^{4}$ Division of Livestock Production and Management, NDRI, Karnal, India \\ *Corresponding author
}

\begin{tabular}{|c|c|}
\hline & A B S T R A C T \\
\hline $\begin{array}{l}\text { Paracetamol, } \\
\text { hepatotoxicity, } \\
\text { Gyrocarpus } \\
\text { asiaticus, zebra } \\
\text { fish, ALT }\end{array}$ & \multirow{3}{*}{$\begin{array}{l}\text { Paracetamol induced hepatotoxicity is a common model for accessing the hepatoprotective } \\
\text { nature of new molecules. This study was conducted to evaluate the potential of aqueous } \\
\text { extract of Gyrocarpus asiaticus on paracetamol induced hepatotoxicity in zebra fish. Fish } \\
\text { were challenged with 20mM concentration of paracetamol followed by treatment with } \\
\text { aqueous extract of Gyrocarpus asiaticus. Serum was evaluated for alanine transferase } \\
\text { (ALT) concentration and liver samples were collected for histopathological analysis. } \\
\text { Result of this study showed that, there was marked elevation of ALT in induced group and } \\
\text { compare to paracetamol induced toxicity group, Gyrocarpus asiaticus treated group has } \\
\text { got marked reduction in ALT which also confirmed through histopathological analysis, } \\
\text { where the treatment group showed normal morphological features. Hence further study can } \\
\text { be done to elucidate the mechanism of action of Gyrocarpus asiaticus through molecular } \\
\text { level to have a confirmation of hepatoprotective nature of this plant. }\end{array}$} \\
\hline Article Info & \\
\hline $\begin{array}{l}\text { Accepted: } \\
17 \text { March } 2019 \\
\text { Available Online: } \\
10 \text { April } 2019\end{array}$ & \\
\hline
\end{tabular}

\section{Introduction}

Drug induced liver injury (DILI) is a major challenge in pharmaceutical industry and drug development (Heidari et al., 2015). DILI due to paracetamol overdose is dose dependant and to an extent, predictable from the dose ingested (Vliegenthart et al., 2014). Marzilawatiet al., (2012) documented the significant association of $3.8 \%$ of ethnicity with hepatotoxicity in Indians. Therefore, improvised models are necessary for predicting DILI and to evaluate alternate hepato-protective agents. The zebrafish is a promising animal for assessing drug induced toxicity in variety of organ systems including liver as zebrafish metabolize drugs using similar pathways as human (Vliegenthart et al., 2014). N-acetylcysteine (NAC) is used as specific antidote for paracetamol induced poisoning but is having some adverse effects like life threatening anaphylactic reactions (Algren, 2008). So as an alternative, natural product can be experimented to sort out the probable hepato-protective effect in a dose dependant manner. Among natural 
compounds, silymarin is a well-known hepatoprotective drug used for the treatment of many liver diseases (Pradhan and Girish, 2006).

Gyrocarpus asiaticus belongs to family Hernandiaceae and found in various parts of India including Eastern Ghats of Tamilnadu (Jayakumar et al., 2008). This plant is reported to have antidiabetic (Yelchuri and Yajaman, 2014), antibacterial (Kanthal et al., 2014), ant helminthic (Kanthal et al., 2013) and anticancer activities (Vithya et al., 2013). According to the perusal of literature there are very scanty reports on hepatoprotective effects of this plant. Vithya et al., (2012) reported on the free radical scavenging activity of this plant which signifies its antioxidant effect.

Hence keeping these criteria in mind this research is undertaken to explore the effect of Gyrocarpus asiaticus on paracetamol induced hepatotoxicity.

\section{Materials and Methods}

\section{Animals}

Adult zebrafish of both sexes (Danio rerio) were purchased from a local pet shop and acclimated in aerated tanks containing distilled water. Zebrafish were fed with commercial fish food twice a day and kept at approximately $28^{\circ} \mathrm{C}$ with a $14 \mathrm{hr}: 10 \mathrm{hr}$ light dark cycle. Each zebrafish weighed 0.2-0.3g and each ten zebrafish were treated in static tanks filled with 2.0 litres of water.

\section{Preparation of aqueous extract of Gyrocarpus asiaticus}

Stem bark portion of Gyrocarpus asiaticuswas collected from the Azhagar Kovil hills, Madurai District, Tamilnadu, India. Twenty gram of powdered plant material was taken in $200 \mathrm{ml}$ conical flask and $100 \mathrm{ml}$ of water was added to it. The mouth of the conical flask was covered with aluminium foil and kept in a orbitals shaker for 24 hours for continuous agitation at 150 rev/min for through mixing. Then the extract was filtered by muslin cloth followed by Whatman no. 1 filter paper and finally filtered by using vacuum evaporator with the water bath temperature of $50^{\circ} \mathrm{C}$. Finally, the residues were collected and used for the experiment.

\section{Acute toxicity study}

Acute toxicity test was performed following OECD guideline no. 203. Aqueous extract of Gyrocarpus asiaticus was dissolved in water. Five ascending concentrations of Gyrocarpus asiaticus aqueous extract (10, 50, 100, 500, $1000 \mathrm{mg} / \mathrm{l})$ were used for the study. After 7 days of acclimatization, seven fish were kept in each 4 litre glass aquarium. A total of 42 zebrafish (including control) were used in this test. During the test fish were not fed. The test was performed using a semistatic method with the solutions renewed every 24 hours. Fish condition and mortality were checked every 24 hours. Experiment was conducted for 96 hours. Water temperature $\left(23 \pm 0.5^{\circ} \mathrm{C}\right)$, $\mathrm{pH}$ (8.3 to 8.61) and oxygen saturation (above $60 \%$ ) were monitored every 24 hours.

\section{Experimental design}

Zebrafish were exposed to paracetamol (20$40 \mathrm{mM}$ ), dissolved in system water for 3 hours (or system water alone for negative controls) (Fig. 1). At $40 \mathrm{mM}$ concentration $80 \%$ mortality was seen within 2 hours of exposure and $60 \%$ of mortality at $30 \mathrm{Mm}$ exposure. So the hepatotoxicity was induced by $20 \mathrm{Mm}$ concentration of paracetamol. This was followed by a change of system water for 221 hours with or without treatment (Table 1). This short exposure to high concentration of 
paracetamol followed by delayed treatment was used to replicate a human single, acute overdose. Experiments were terminated 5-24 hours after the start of paracetamol exposure (Vliegenthart et al., 2014). After treatment for 24 hours, zebrafish were anaesthetized using melting ice. Blood was collected using established lateral incision (LI) technique. Then fish were euthanized in melting mice. The liver tissues were separated and used immediately for biochemical analysis. Serum was separated by centrifuging the blood at $2500 \mathrm{rpm}$ for 15 minutes and analysed for acute marker for cellular integrity i.e., alanine aminotransferase (ALT) was estimated in the serum by kinetic method using stanadard kits (Agappe Diagostics).

\section{Histopathology}

After sacrifice, portions of the liver were collected and fixed in neutral buffer formalin (NBF) for histopathological examination. Sections were cut at $5 \mu \mathrm{m}$ thickness, stained with haematoxylin and eosin $(\mathrm{H} \& \mathrm{E})$. The sections were then viewed under light microscope for histopathoogical analysis.

\section{Statistical analysis}

The results were expressed as mean \pm standard error (SE). The differences between groups were determined by using the statistical package for social sciences (SPSS) software package for windows. The effects of treatments were determined by analyzing the data using one-way ANVA followed by Duncan's multiple comparison tests. $\mathrm{P}$ values
$<0.05$ or $<0.01$ were considered as statistically significant.

\section{Results and Discussion}

Treatment with $1000 \mathrm{mg} / \mathrm{ml}$ resulted in death of $15 \%$ fishes in that group in $96 \mathrm{hr}$ toxicity study whereas in other groups death was invariably low. So it was suggestive of $\mathrm{LD}_{50}$ value is higher than $1000 \mathrm{mg} / \mathrm{ml}$. As per the OECD guideline, at a limit dose $100 \mathrm{mg} / \mathrm{l}$ fish showed no mortality indicating that at $99 \%$ confidence level, can also be concluded that $\mathrm{LD}_{50}$ value is higher than $100 \mathrm{mg} / \mathrm{ml}$. As the dosing is concern, 1/10th of the highest dose tested was used as the therapeutic dose in the study. In the present study, paracetamol treated group showed an increase in serum ALT activity (Fig. 2). Administration of Gyrocarpus asiaticus revealed a decrease in serum ALT activity up to normal level, which is similar to that of the standard drug silymarin at the given dose. As per histopathology reports, untreated zebrafish liver showed normal tissue and cell structure, tight cell contact and liver was filled with polygonal cells with well-preserved cytoplasm and prominent nucleus (Fig. 3A.). Paracetamol treatment increased vacuolar degeneration, hepatocyte necrosis and area of focal congestion and haemorrhage (Fig. 3B). As demonstrated in the Figure 3B1, paracetamol treated liver shows loose cell-tocell contact with dissociated and irregular cells with various grades of small and large vacuoles and amount of hepatic parenchyma decreased.

Table.1 Experimental design

\begin{tabular}{|l|l|l|}
\hline GROUPS & TREATMENTS & No. of fish \\
\hline I & Untreated control & 24 \\
\hline II & Paracetamol Control & 24 \\
\hline III & Paracetamol + Standard drug (Silymarin) & 24 \\
\hline IV & Paracetamol + Gyrocarpus asiaticus & 24 \\
\hline
\end{tabular}


Fig.1 Zebrafish and its liver after induction with hepatotoxicity
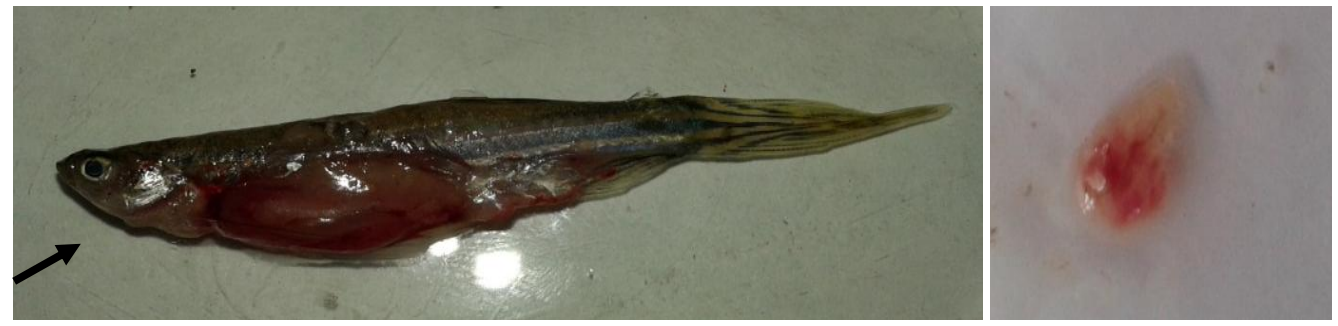

Liver- Paracetamol induced hepatotoxicity-Haemorrhage

Fig.2 Serum ALT

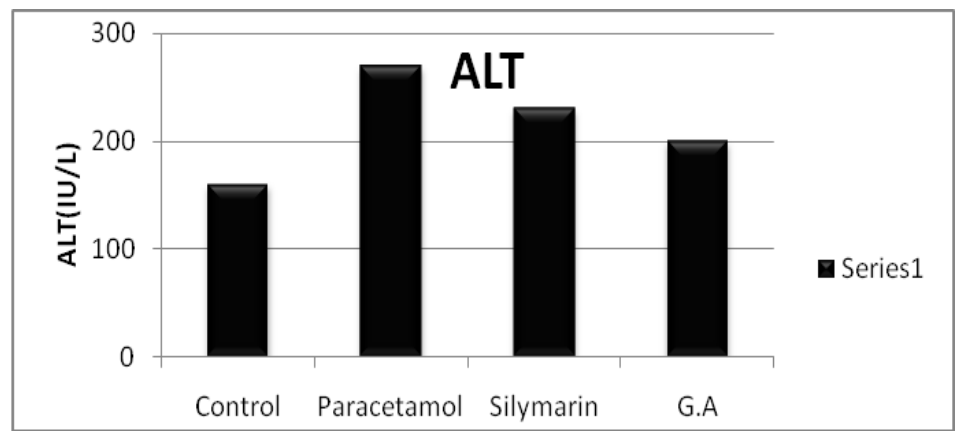

Histogram shows effects of paracetamol, silymarin, Gyrocarpus asiaticus (G.A) on ALT level pooled sample of serum

Fig.3 Histopathological study of liver
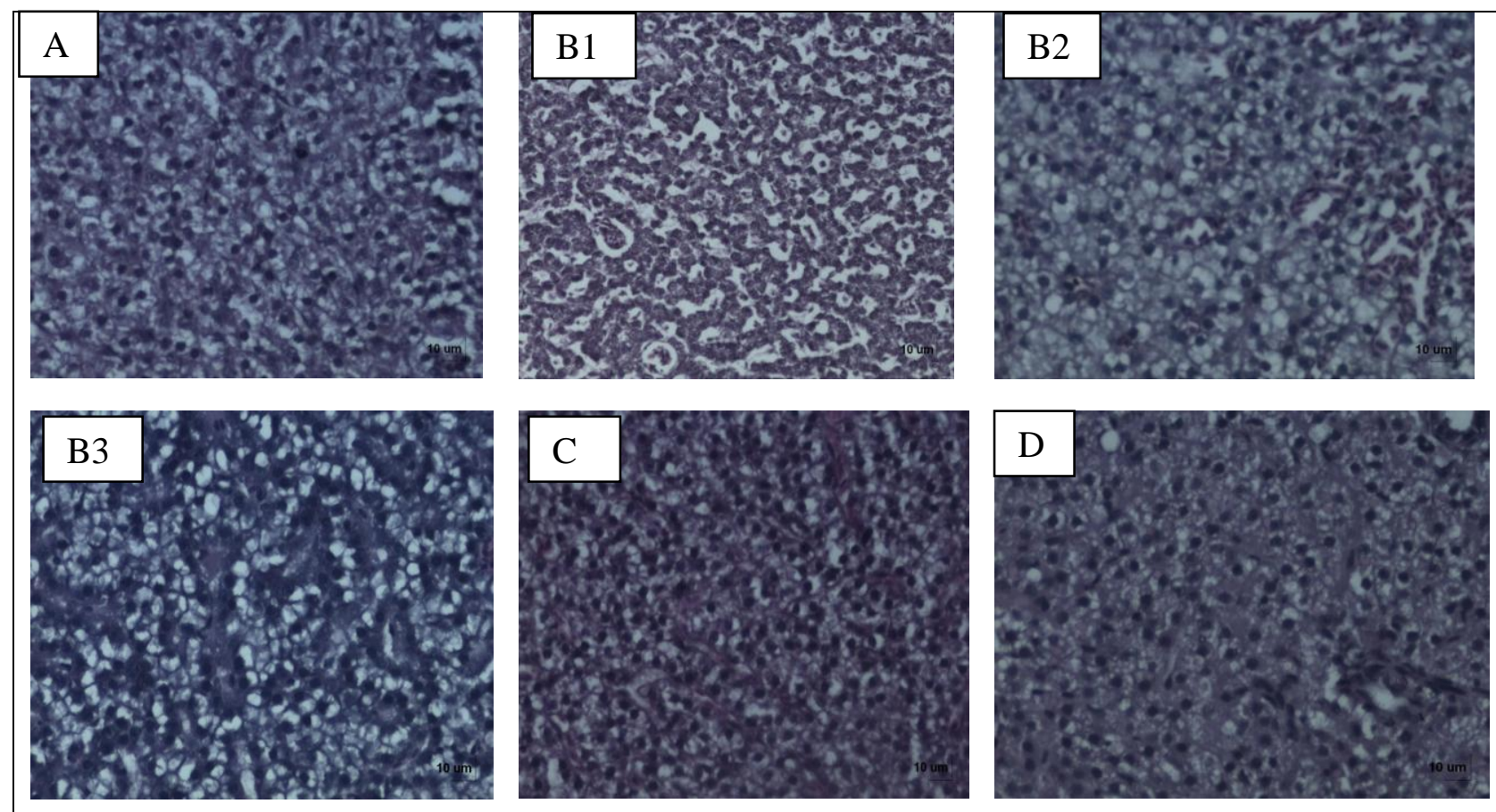

Histological images of adult zebrafish liver, A- control-Liver- normal, B- 1:Paracetamol-Liver loose cell-to-cell contact-diffuse, 
2: Vacuolar degeneration- congestion-haemorrhage, 3: Vacuolar degeneration, C- Silymarin-Liver- Mild change, D- G.A -LiverMild vacuolar degeneration

Treatment with silymarin causes mild changes in hepatocytes (Fig. 3C) whereas treatment with Gyrocarpus asiaticus caused vacuolar degeneration with mild congestion (Fig. 3D).

For patients presenting with paracetamolinduced liver failure, the only reliable parameters to provide therapeutic guidance is ALT serum level. North et al., (2010) and Shivashri et al., (2013) also found an increase in ALT value in paracetamol induced hepatotoxicity in zebra fish.

Increase in ALT activity in blood of paracetamol-exposed fish reveals paracetamol induced liver tissue damage. ALT and AST are two mitochondrial enzymes (Gharaei et $a l ., 2011$ ) and are found in the cell cytoplasm in higher concentrations particularly ALT. Higher levels of these intracellular enzymes in serum might be a result of leakage from cells due to cell membrane damage.

As per histopathology is concern Gyrocarpus asiaticus could able to decrease the inflammatory lesions, but not completely restore the normal architecture of liver. As it was an acute study, for reverting back from degenerative state to normal state needs time and treatment for longer period could have restore the architecture of liver to normal state in zebra fish. However, the liver histology was comparatively improved and shown less congestion than paracetamol toxicity group.

Hence in conclusion, zebrafish acts as a physiologically relevant model of paracetamol hepatotoxicity. Here, we use a variety of biochemical, histological, and clinical outcome measures to show the overall relevance of the zebrafish paracetamol toxicity model to human physiology. Further study can be performed with molecular pathway analysis to unravel the potential of Gyrocarpus asiaticus in hepatotoxicity model with variable doses.

\section{Acknowledgement}

This work was funded by Tamilnadu Veterinary and Animal Sciences University and research was carried out during $\mathrm{PhD}$ of the first author in Dept of Veterinary Pharmacology and Toxicology. Our sincerely thanks to Dr. S. Vairamuthu, Associate Professor and Head, Centralized Clinical Laboratory, Madras Veterinary College, for his kind help in carrying out the biochemical and hematological study. Also, I want to acknowledge Dr. M. R. Srinivasan for guiding me in related to procurement and maintained of Zebrafish in laboratory conditions.

\section{References}

Algren, DA., Review of N-Acetylcysteine for the treatment of acetaminophen (Paracetamol) toxicity in pediatrics. Second meeting of the subcommittee of the expert committee on the selection and use of essential medicines, 2008.

Gharaei, A., Ghaffari M, Keyvanshokooh S, Akrami R. Changes in metabolic enzymes, cortisol and glucose concentrations of Beluga (Huso huso) exposed to dietary methyl mercury. Fish Physiol Biochem 2011; 37:485493.

Heidari R, Niknahad H, Jamshidzadeh A, M. AE, Abdoli N. An overview on the proposed mechanisms of antithyroid drugs-induced liver injury. $A d v$. Pharm Bull. 2015; 5: 1-11.

Jayakumar, S., Ramachandran A, Bhaskaran G, Heo J. Forest dynamics in the Eastern Ghats of Tamilnadu, India. Environmental Management. 2008; DOI 10.1007/s00267-008-9219-y.

Kanthal ,LK., Dey A, Satyavathi K, Bhojaraju P. Antibacterial potential of 
methanolic extract of Gyrocarpus asiaticus wild. Asian J. Pharm Clin Res 2014; 7: 192-194.

Kanthal, L.K., A. Dey, K. Satyavathi, P. Bhojaraju, 2013. Evaluation of anthelmitic activity of Gyrocarpus asiaticus wild and Lacuta runcinata DC on the pheritima model. Int J. Pharm Pharm Sci.5: 273-275.

Marzilawati, AR., YY Ngau and Mahadeva S. Low rates of hepatotoxicity among Asian patients with paracetamol overdose: a review of 2014 cases. BMC Phamacologyandtoxicology. 2012;13:http://www.biomedcentral.co $\mathrm{m} / \mathrm{bmcpharmacoltoxicol} \quad / 2050$ 6511/13/1/8.

North, TE, Babu IR, Trista EL, Vedder M, Lord AM, Wishnok JS, Tannenbaum SR, Leonard IZ, Wolfram G. PGE2regulated wnt signaling and $\mathrm{N}$ acetylcysteine are synergistically hepatoprotective in zebrafish acetaminophen injury. PNAS 2010; 107: $17315-17320$.

OECD GUIDELINE FOR TESTING OF CHEMICALS-203-Fish, Acute Toxicity Test. Adopted: 17.07.92 Adopted by the Council on 17th July 1992.

Pradhan, SC., and Girish C. Hepatoprotective herbal drug, silymarin from experimental pharmacology to clinical medicine. Indian J Med Res., 2006; 124: 491.

Shivashri, C., Rajarajeshwari T and Rajasekar P. Hepatoprotective action of celery (Apium graveolens) leaves in acetaminophen-fed freshwater fish (Pangasius sutchi). Fish Physiol Biochem 2013; DOI 10.1007/s10695012-9762-6.

Vithya, T., Kavimani S, Rajkapoor B. Anticancer activity of Gyrocarpus asiaticus and Sophora interrupta on daltons lymphomaascites (DLA) induced mice. WJPPS. 2013; 2: 66136618.

Vithya, T., V. Kavimani, B. Rajkapoor, K. Alhasjajiju, J.L enojenita, 2012. Free radical scavenging activity of Gyrocarpus asiaticus by using DPPH and ABTS method. IJPCBS. 2: 155158.

Vliegenthart, ADB, Tucker CS, Pozo JD and Dear JW. Zebrafish as model organisms for studying drug induced liver injury. $\mathrm{Br} J$ Clin Pharmacol 2014; 78: 1217-1227.

Yelchuri, P., and Yajaman S., Assessment of antidiabetic activity of ethanolic extracts of Gyrocarpus asiaticus wild bark against streptozocin induced diabetes in rats. IJAPBC 2014; 3: 6071.

\section{How to cite this article:}

Baisakhi Moharana, S.P. Preetha, C. Balachandran, Acharya, P. 2019. Hepatoprotective Effect of Aqueous Extract of Gyrocarpus asiaticus on Paracetamol Induced Hepatotoxicity in Zebra Fish. Int.J.Curr.Microbiol.App.Sci. 8(04): 2260-2265.

doi: https://doi.org/10.20546/ijcmas.2019.804.264 